\title{
Balloon Angioplasty for Ductus Arteriosus in Infant With Ductal Origin of the Left Pulmonary Artery _ Combination With Nitrogen Inhalation Therapy
}

\author{
Hisashi Sugiyama, MD; Minako Hoshiai, MD; Atsushi Naito, MD; \\ Shoji Suzuki, MD*; Sinpei Nakazawa, MD
}

\begin{abstract}
An infant with truncus arteriosus (Van Praagh A3; isolated left pulmonary artery (LPA) and ductal origin of the LPA) had an extremely stenotic ductus arteriosus (DA) and the LPA could not be demonstrated. As a salvage operation, balloon angioplasty was performed for the stenotic DA at 8 days of age. The minimum lumen diameter of the DA increased from 0.7 to $2.7 \mathrm{~mm}$. After the procedure, the LPA tree was well demonstrated and total pulmonary blood flow increased. Nitrogen inhalation was begun with a nasal positive airway pressure system in order to regulate pulmonary blood flow. Repeat balloon angioplasty was performed at 33 days of age for the restenosed DA. The infant's general condition was stabilized until undergoing pulmonary artery reconstruction and modified Blalock-Taussig shunt at 4 months of age, and definitive repair at 11 months of age. The combination of balloon angioplasty and nitrogen inhalation therapy enabled simultaneous growth of the LPA tree and regulation of total pulmonary blood flow, which could be a useful strategy for complex congenital heart diseases with unbalanced pulmonary blood flow. (Circ J 2007; 71: 445-447)
\end{abstract}

Key Words: Balloon angioplasty; Ductus arteriosus; Isolated pulmonary artery; Nitrogen inhalation; Truncus arteriosus

$\mathbf{I}$ solated pulmonary artery is occasionally seen in children with tetralogy of Fallot, pulmonary atresia with ventricular septal defect, heterotaxia syndromes, and truncus arteriosus. In such cases, stenosis or occlusion of the proximal portion of the isolated pulmonary artery frequently occurs because of constriction by the ductal tissue, so management of the stenosis is a critical concern.

Clinical experience of catheter intervention for the ductus arteriosus (DA) remain limited ${ }^{1-5}$ and the indications are controversial. Both balloon angioplasty (BA) and stent implantation can potentially result in re-stenosis or complete occlusion 3,6 Furthermore, stent implantation could interfere with any subsequent surgery. We report our experience using a combination of BA for the stenotic DA and nitrogen inhalation therapy in an infant with complex congenital heart disease with non-confluent unbalanced pulmonary blood flow.

\section{Case Report}

A 2-day-old baby was referred because of heart murmur and cyanosis. He was diagnosed as having truncus arteriosus (Van Praagh type A3; ductal origin of the left pulmonary artery (LPA)). Color Doppler echocardiography showed trace blood flow in the DA. High-dose prostaglandin E1$\mathrm{CD}$ was intravenously administered to open the DA, but

(Received May 10, 2006; revised manuscript received November 13, 2006; accepted December 11, 2006)

Departments of Pediatrics, *Second Surgery, Faculty of Medicine, University of Yamanashi, Yamanashi, Japan

Mailing address: Hisashi Sugiyama, MD, Department of Pediatrics, Faculty of Medicine, University of Yamanashi, 1,110 Shimokato, Chuo, Yamanashi 409-3898, Japan. E-mail: shisashi@yamanashi.ac. jp was not effective. At the age of 8 days, catheter examination and angiography were performed after his parents gave written informed consent.

The infant was heparinized during the procedure $(150 \mathrm{IU} / \mathrm{kg})$. Aortography revealed an extremely narrow DA, which connected to the LPA, and the distal pulmonary artery tree could not be demonstrated (Fig 1a). To salvage the LPA, a J-type guide wire (0.035 Radifocus, Terumo, Japan) was advanced with slight resistance through a 4Fr Judkins left-type catheter and the stenosis was dilated using a balloon catheter $(4 \times 20 \mathrm{~mm}$, Power Flex P3, Cordis Corp, FL, USA) at $6 \mathrm{~atm}$. The balloon size was $150 \%$ of the reference diameter of the distal LPA. The minimal lumen diameter (MLD) significantly increased from $0.7 \mathrm{~mm}$ to $2.7 \mathrm{~mm}$ after the procedure (Fig 1b). Oxygen saturation in the systemic artery slightly increased from $90 \%$ to $92 \%$ on room air and the left-to-right pulmonary perfusion ratio on the pulmonary perfusion scan significantly increased from 0.03 to 0.15 . During the follow-up, the cardiothoracic ratio (CTR) on chest X-ray increased from 0.59 to 0.63 and tachypnea of 50/min developed gradually with physiological dropping of pulmonary arterial resistance and increased pulmonary blood flow. Therefore, nitrogen gas was administered through a nasal positive airway pressure inhalation system at approximately 0.18 of the inspiratory oxygen fraction. Immediately after initiation of hypoxic therapy, the arterial systolic pressure dramatically increased from $46 \mathrm{mmHg}$ to $68 \mathrm{mmHg}$ and urination also increased. Three weeks after the procedure, echocardiography revealed diminished left pulmonary blood flow again, so at the age of 33 days, repeat BA was performed as before. The MLD increased from $1.8 \mathrm{~mm}$ to $2.7 \mathrm{~mm}$. There were no complications or difficulties during either procedure. After the second intervention, stenosis of the DA was not observed 


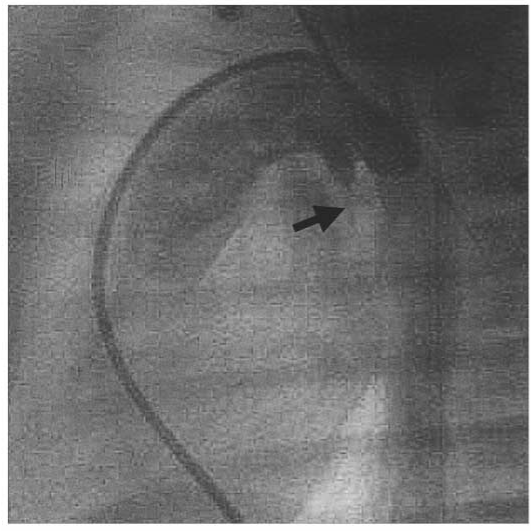

a

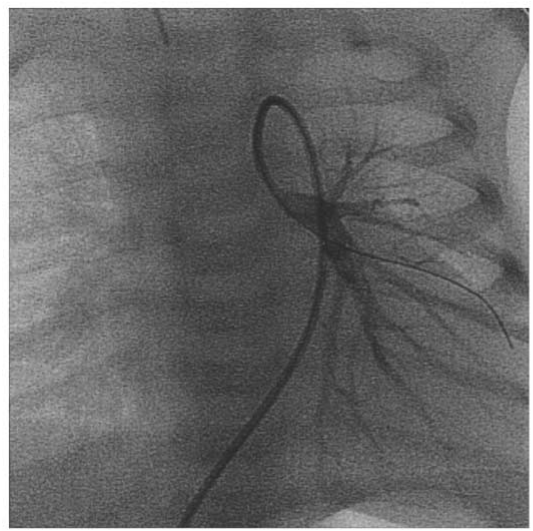

a

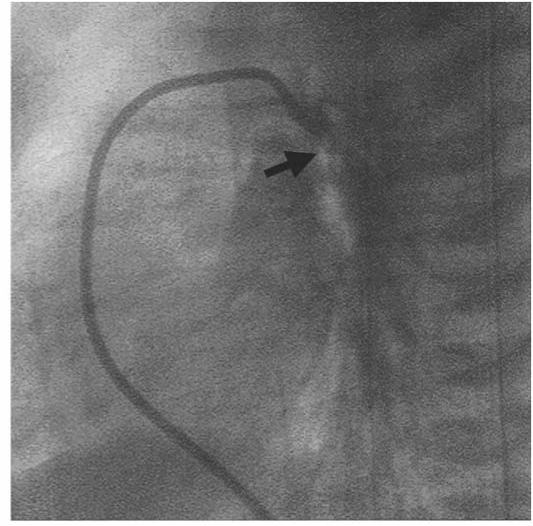

b

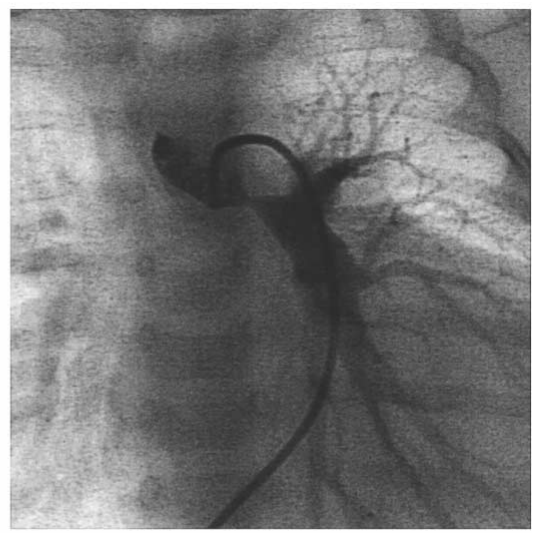

b
Fig 1. (a) Before the first procedure, aortography shows a trace of ductal arteriosus in the lateral view (arrow). The distal left pulmonary artery can not be seen. (b) After the procedure, the stenosis of the ductus arteriosus has been dilated (arrow) and the distal left pulmonary artery can be seen. on color Doppler echocardiography until surgery.

The baby's body weight increased from $2,580 \mathrm{~g}$ at the starting of nitrogen inhalation to $3,556 \mathrm{~g}$ just before surgery. The CTR decreased from 0.62 to 0.59 before surgery and on the last pulmonary perfusion scan the left-to-right pulmonary perfusion ratio was 0.16 . Clinically, pulmonary blood flow was well controlled and his general condition stabilized until surgery. The pre-operative angiogram showed a patent DA and developed distal LPA tree (Figs 2a,b).

At the age of 4 months the infant underwent pulmonary artery reconstruction, right modified Blalock-Taussig shunt, and truncus valve repair as a first stage procedure. Subsequently, closure of the ventricular septal defect and right ventricular outflow reconstruction using auto-pericardium were performed as the definitive repair at 11 months of age, without any problems. Pulmonary hypertension was not observed at 2 years after surgery.

\section{Discussion}

Although surgical repair of truncus arteriosus with Van Praagh type A3 has been described, ${ }^{7-9}$ rescue of the distal LPA is a critical concern for definitive repair. In the present case, the LPA was not well developed because of the shortage of blood supply at birth. Furthermore, the low birth weight was a risk factor for palliative open-heart surgery, and for first-stage definitive repair. In addition, aortic or pulmonary homograft is practically unavailable in Japan, so a 2-stage surgical repair is used. To salvage the isolated obstruction of the LPA, a Blalock-Taussig shunt is an option, ${ }^{10}$ and stent implantation for the DA is another? However, both procedures are invasive and could result in excessive pulmonary blood flow in a child with high pulmonary blood flow disease. Although several studies have reported the usefulness of stent implantation for the DA, it can be fatal, because acute in-stent obstruction frequently occurs!-6 Furthermore, the stent can interfere with subsequent surgical repair and require removal. Although BA has the potential risk of rupture or re-stenosis of the DA, it is less invasive than stent implantation and will not affect any subsequent surgery. Histologically, the tissue of the ductus artery is fragile, so the aim of BA for the DA is not to fully open the stenosis but to rescue the distal pulmonary artery. In the present case, the size of the BA catheter we selected was large enough to reopen and maintain the DA, but would not cause vessel rupture or excessive pulmonary perfusion. Re-stenosis occurred 3 weeks after the first procedure, but the efficacy of the second catheter intervention was maintained for longer than that of the first catheter intervention. The mechanism of the re-stenosis of the DA was considered to be transformation of the smooth muscle cell phenotype and proliferation of smooth muscle cells into the subendothelial tissue (ie, neointimal proliferation) triggered by the $\mathrm{BA} !^{1}$ Additional $\mathrm{BA}$ for remodeling the ductus tissue might be more effective than the first inflation. Careful echocardiographic follow-up is necessary to detect re-stenosis of the DA.

In order to perform BA for the DA in children with excessive pulmonary blood flow, restriction of the pulmonary 
blood flow is necessary. Currently, inhalation therapy with low oxygen concentration is essential treatment in congenital heart disease with increasing pulmonary blood flow. Nitrogen or carbon dioxide inhalation therapy is used for complex congenital heart disease with high pulmonary blood flow, such as hypoplastic left heart syndrome, and the efficacy and safety of this therapy has been proved!2,13 We used nitrogen inhalation through a nasal positive airway pressure system, which does not require intubation and thus allows oral milk feeding, and pulmonary blood flow can be well regulated. Consequently, the infant gained body weight and his condition was stabilized until surgery.

We conclude that the combination of the BA for the DA and nitrogen inhalation therapy is a feasible and effective strategy for children with an isolated pulmonary artery and unbalanced pulmonary blood flow.

\section{References}

1. Benson LN, Freedom RM. Balloon dilatation of the very small ductus arteriosus in preparation for transcatheter occlusion. Catheter Cardiovasc Diag 1989; 18: $48-49$.

2. Gibbs JL, Rothman MT, Rees MR, Parsons JM, Blackburn ME, Ruiz CE. Stenting of the arterial duct: A new approach to palliation for pulmonary atresia. Br Heart J 1992; 67: 240-245.

3. Peirone P, Lee K, Yoo S, Musewe N, Smallhorn J, Benson L. Staged rehabilitation of ductal origin of the left pulmonary artery in an infant Fallot's tetralogy. Catheter Cardiovasc Intervent 2003; 59: $392-$
395.

4. Rosenthal E, Qureshi SA, Tynan M. Percutaneous pulmonary valvotomy and arterial duct stenting in neonates with right ventricular hypoplasia. Am J Cardiol 1994; 74: 304-306.

5. Suarez de Lezo J, Lopez-Rubio F, Guzman J, Galan A, Herrera N, Arizon J, et al. Percutaneous transluminal angioplasty of stenotic ductus arteriosus. Catheter Cardiovasc Diag 1985; 11: 493-500.

6. Gibbs JL, Uzun O, Blackburn ME, Wren C, Hamilton JR, Watterson KG. Fate of the stented arterial duct. Circulation 1999; 99: $2621-$ 2625.

7. Barbero-Marcial M, Atik E, Baucia JA, Pradel HO, Macruz R, Jatene $\mathrm{AD}$. Reconstruction of stenotic or nonconfluent pulmonary arteries simultaneously with a Blalock-Taussig shunt. J Thorac Cardiovasc Surg 1988; 95: 82-89.

8. Guadalupi P, Spadoni I, Vanini V. Repair of hemitruncus with autologous arterial ring and valved bioconduit. Ann Thorac Surg 2000; 70: $1708-1710$.

9. Ziemer G, Luhmer I, Siclari F, Kallfelz HC. Truncus arteriosus type A3: Complex repair with cryopreserved pulmonary homograft. Eur $J$ Cardiothorac Surg 1987; 1: 110-115.

10. Jedeikin R, Rheuban KS, Carpenter MA, Kron IL. Ductal origin of the left pulmonary artery in severe tetralogy of Fallot: Problems in management. Pediatr Cardiol 1984; 5: 323-326.

11. Takahashi K, Ino T, Ohkubo M, Akimoto K, Kishirou M. Restenosis after balloon angioplasty of coarctation: Relationship with ductus arteriosus. Pediatr Int 2000; 42: 658-667.

12. Day RW, Barton AJ, Pysher TJ, Shaddy RE. Pulmonary vascular resistance of children treated with nitrogen during early infancy. Ann Thorac Surg 1998; 65:1400-1404.

13. Jobes DR, Nicolson SC, Steven JM, Miller M, Jacobs ML, Norwood WI Jr. Carbon dioxide prevents pulmonary overcirculation in hypoplastic left heart syndrome. Ann Thorac Surg 1992; 54: 150-151. 